\title{
PRODUCTIVIDAD Y RENTABILIDAD DE LA MANO DE OBRA ESCLAVA EN EL DESARROLLO DE LA PLANTACION CUBANA
}

\author{
POR \\ PABLO TORNERO \\ Departamento de Historia de América. \\ Universidad de Sevilla
}

Uno de los temas que siguen pareciendo más sugerentes para el americanista español es el de la esclavitud en las Indias hispanas. Y ello por dos motivos a simple vista importantes: Primero, por los efectos que este modo de producción tuvo sobre la historia de unos países, donde ese régimen laboral fue predominante para la implantación de un determinado modelo económico, que les ha supuesto en el presente una herencia de monoproducción, subdesarrollo y dependencia. Es decir importa mucho conocer ese pasado colonial para poder analizar hoy su situación y para explicar históricamente los orígenes de sus limitaciones económicas actuales. En segundo lugar, éste aspecto de la historia de América hispana se presenta como importante, por la escasez general de trabajos sobre esa materia. Muy pocos han sido, hasta el momento, los realizados por la historiografía nacional. Ello es en parte explicable, porque el sistema de producción esclavista, tuvo pocos efectos en los grandes núcleos coloniales, objeto de la mayoria de la historiografía latinoamericana y española. Esa falta de tradición, en este tipo de temas, también, en algún modo, es un producto de la escasez general de estudios, por parte española, sobre la economia interna de América, más volcada hacia trabajos en los que el continente es un punto referencial dentro del sistema del Estado español, sea en el orden político, administrativo, religioso o de los intercambios. En este sentido, la cuestión esclavista, ha sido objeto de monografías sólidas y bien documentadas, que hacen referencia a la trata negrera, desde un punto de vista político-comercial, o en otros casos a la incidencia 
de la esclavitud y sus efectos económicos en el sistema mercantil metropolitano (1).

Contamos, sin embargo, con importantes aportaciones sobre esta temática, desarrolladas sobre todo por historiadores cubanos. No en valde, Cuba fue el territorio americano donde la esclavitud tuvo una incidencia mayor a la hora de configurar su sistema económico, y donde este modo de producción afectó de una manera más general a todos los ámbitos de su devenir, tanto que fue capaz de configurar su proceso histórico. La bibliografía cubana, a este respecto, se ha ocupado de la esclavitud en sus más variados órdenes, desde su planteamiento teórico a niveles económicos o de clase, hasta trabajos de más contenido documental que hacen referencia a su incidencia en la producción, pasando por reflexiones acertadas sobre su papel en los cambios políticos ocurridos en la isla (2). En gran parte, los que nos dedicamos al estudio de la plantación esclavista en Cuba, somos deudores directos de sus enseñanzas y sobre todo de su metodología. Y es que en ese sentido, estamos plenamente de acuerdo en afirmar que el análisis de la esclavitud, cobra su verdadera dimensión, cuando se plantea como un modo de producción capaz de generar un sistema económico, una clase que lo sustenta y una superestructura que lo respalda.

En este trabajo, queremos plantear una cuestión que en otros estudios recientes ya habíamos enunciado utilizando distintas fuentes documentales. Se trata de analizar el papel de la mano de obra esclava en la formación y desarrollo de la plantación en Cuba, desde dos aspectos destacados. Su capacidad productiva y

(1) Enriqueta VILA Vular en Hispanoamérica y el comercio de esclavos. Sevilla, 1977 y en "El Consulado de Sevilla, asentista de esclavos: una nueva tentativa para el mantenimiento del monopolio comercial". En Primeras Jornadas de Andalucia y América Huelva, 1981. Jordi MALUQuer DE MOTES: "La Burguesía catalana y la esclavitud en Cuba: Política y Producción". En Revista de la Biblioteca Nacional José Martí La Habana, 1976. E. HeRnÁndez SandoICA: "La navegación a Ultramar y la acción del Estado: España, siglo XIX". Esiudios de Historia Social, n. ${ }^{\circ} 44$ y 47 . Madrid, 1988. Importante es el libro colectivo, coordinado por Francisco DE SOLANO y A. GUIMERA, Esclavitud y derechos humanos. La lucha por la libertad del negro en el siglo XIX. Biblioteca Historia de América, $\mathrm{n}^{2} 1$, Centro de Estudios Histónicos. Madrid, 1990.

(2) M. Moreno Fraginals: El Ingenio. La Habana, 1978. A. Sorhegul: "El surgimiento de una aristocracia colonial en el occidente de Cuba en el siglo XVI", Santiago. Santiago de Cuba, 1980, $n^{2}$ 37, págs. 147-209. M." del C. BARCL: "Lá esclavitud de las plantaciones. Una relación secundaria". Revista Cubana de Ciencias Sociales, La Habana, $n^{2}$ 7, 1985. Fe IGLESLA: "Algunas consideraciones en torno a la abolición de la esclavitud". La Esclavitud en Cuba, La Habana, 1986. E. TORRES-Cuevas y E. REyes: Esclavitud y Sociedad. La Habana, 1986. Doria GONZÁLEZ FERNÁNDEZ: "La economía cafetalera cubana: 1790-1860". Arbor, Madrid, 1991. 


\section{GRAFICA 1. ESCLAVOS POR INGENIOS SEGUN EXTENSION EN CABALLERIAS}

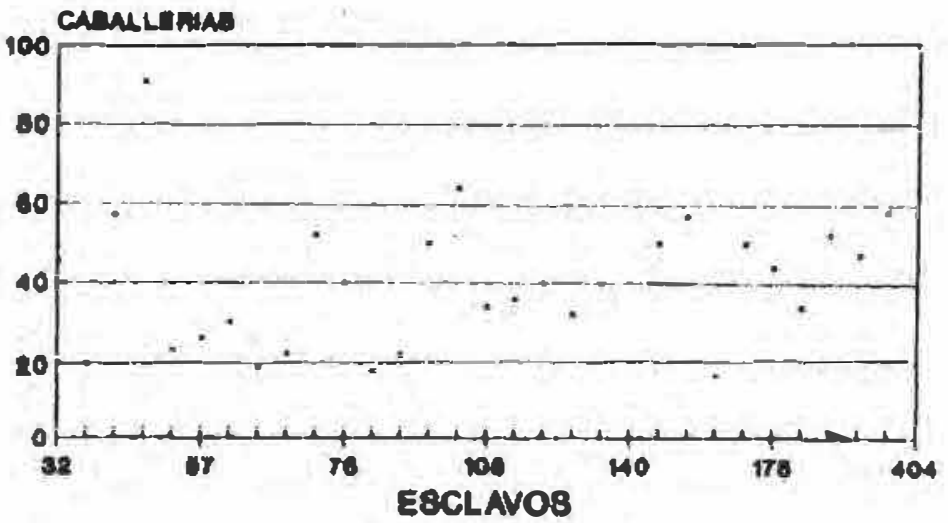

GRÁFICA 2. NUMERO DE ESCLAVOS Y PRODUCCION POR INGENIO

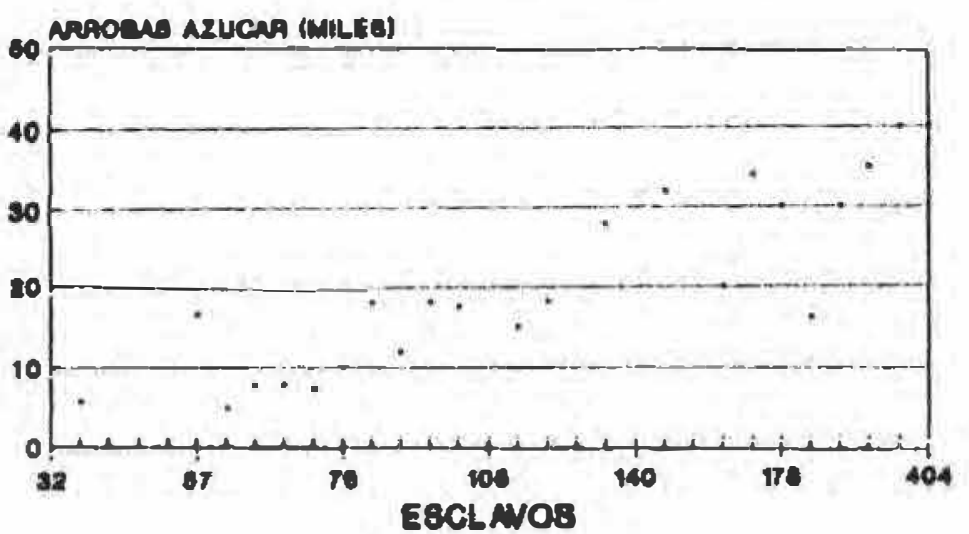

\section{GRAFICA 3. NUMERO DE CABALLERLAS $Y$} PRODUCCION POR INGENIO

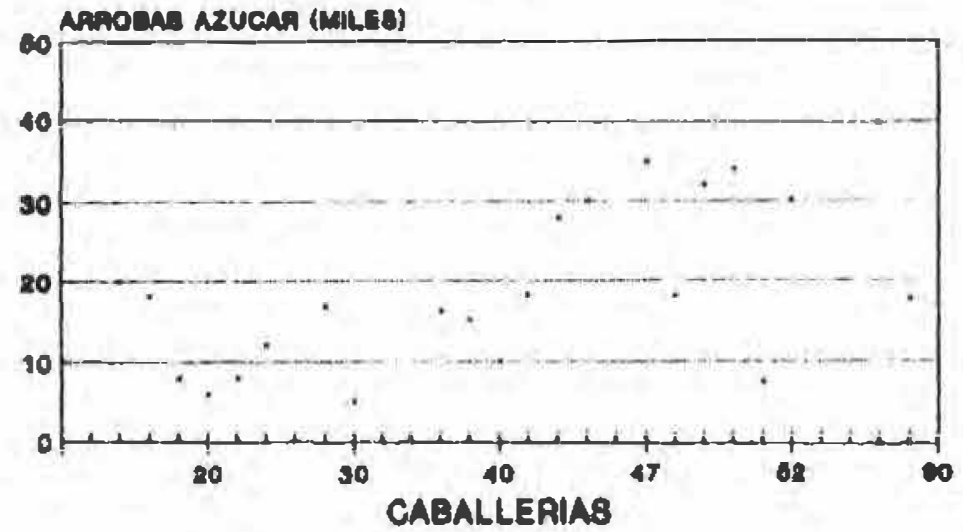


su rentabilidad. En efecto, dentro del sistema económico azucarero cubano, uno de los aspectos más sugerentes es el estudio de los esclavos que componían la masa laboral de los ingenios. En suma, analizar al esclavo dentro del engranaje de la plantación azucarera. Y es que, en efecto, a veces se contempla la figura del esclavo en general, olvidando su dedicación laboral. Intentar estudiar al esclavo sin ponerlo en relación con su proyección y utilización económica es ignorar el funcionamiento del sistema esclavista en la isla de Cuba.

Proponemos en este trabajo analizar la figura del esclavo en Cuba, entre 1784 y 1837, repartidos en treinta y un ingenios de distinto tamaño en extensión y producción. En total una masa esclava de 2.981 negros, que componian la mano de obra de dichos ingenios, de los que poseemos datos sobre sus caracteres demográficos, su dedicación laboral y su valor monetario (3).

\section{La dotacion de negros del ingenio. Productividad}

La dotación de negros en los casi tres mil ingenios estudiados, variaba extraordinarimente (Apéndice I). Junto a algunos que no llegaban a los ochenta esclavos, existian otros con más de doscientos e incluso dos de más de trescientos. Ello no se correspondía exactamente con la extensión del ingenio. Es decir, no es siempre válido decir que a mayor número de caballerías, mayor cantidad de esclavos. La Gráfica 1 permite observar este hecho con bastante claridad. Normalmente el hacendado disponia de la tierra antes de la fundación de su plantación, usualmente como un patrimonio adquirido por herencia, por lo que no debía invertir capital en su compra. En cambio, no todos los hacendados disponían del capital o el crédito suficientes para adquirir todos los esclavos que requiriese el tamaño de su propiedad. De modo general, podemos decir, a partir de nuestros datos, que la cifra media de esclavos por ingenio era -entre los años estudiados, 1784-1837- de 127 y el promedio de caballerias por predio

(3) Toda la documentacién manejada en este trabajo, procede de la tasación de los ingenios referidos en el Apéndice I y ha sido investigada en el Archivo Nacional de Cuba. Sección Protocolos Notariales. Quiero agradecer expresamente la ayuda prestada por las prof esoras Fe Iglesias y Doria González, del Instituto de Historia de Cuba en la búsqueda y obtención de estos datos en el citadu archivo. 
azucarero de 37,71 . En este sentido, es necesario subrayar que no es riguroso plantear el si un ingenio tenía muchos o pocos esclavos, si ello no está acompañado de su nivel de productividad y beneficio. Es absolutamente cierto, a priori, que a mayor dotación de esclavos, mayor productividad y que, desde luego, es el factor trabajo, más que el factor tierra, el que hace obtener del ingenio una producción más elevada, con diferencia, como explican las Gráficas 2 y 3. De hecho en la fincas azucareras cubanas el crecimiento productivo, en la época estudiada, se generó a base de incrementar el número caballerias dedicadas a este cultivo y a base de desarrollar sus dotaciones de esclavos y, en menor medida, potenciando nuevas técnicas y métodos en la producción.

Sin embargo hay que subrayar que este planteamiento general es una verdad a medias que puede conducir a errores a la hora de definir el papel del factor trabajo esclavo en los ingenios de Cuba. Y es que entre los esclavos también existe una productividad física media y una productividad física marginal. A veces un número excesivo de negros para la cantidad de caballerías de un ingenio, podía conducir a un rendimiento decreciente. De la misma manera que una escasa dotación de esclavos, sobre una gran extensión, llevaría a hacer decrecer la producción a medida que el trabajo se distribuía sobre un área cada vez mayor. Para ello se ofrecen ejemplos significativos en el Apéndice 2. Ello nos permite decir que no es por tanto absolutamente exacto decir que para hacer aumentar la producción, bastaba incrementar la dotación de esclavos o incorporar más caballerías al ingenio. Parece más conveniente afirmar que era necesario adecuar el número de operarios a la extensión sembrada de caña y viceversa, para conseguir una óptima producción con los menores costes posibles. Es decir que, en este sentido, el ingenio funciona como cualquier unidad productiva, sometida a leyes productivas comunes. Con la documentación analizada, podemos corroborar este hecho y asi la Gráfica 4, nos permite ver que el aumento de esclavos por caballería no necesariamente lleva aparejado una mayor producción en el ingenio, debido sobre todo a los rendimientos decrecientes, como se observa también en la Gráfica 5, donde las arrobas producidas por esclavo no concuerdan con el número de éstos por caballería, debido al mismo fenómeno de inadecuación del número de esclavos a la extensión de tierra cultivada por ellos. De la misma manera la Gráfica 6 define esta 
GRIFICA 4. ESCLAVOS POR CABALLERLA Y PRODUCCION POR INGENIO

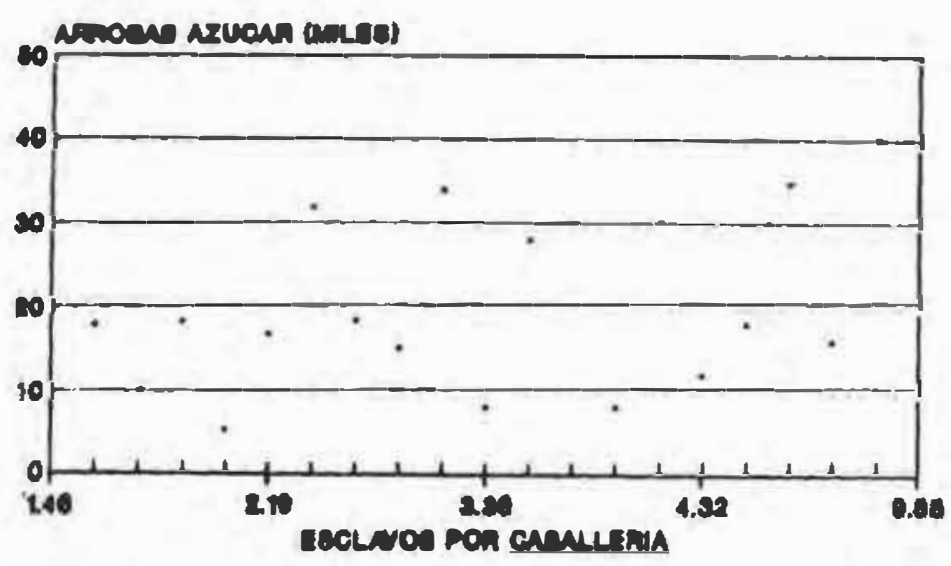

GRAFICA 5. ESCLAVOS POR CABALLERIA Y PRODUCCION POR ESCLAVO

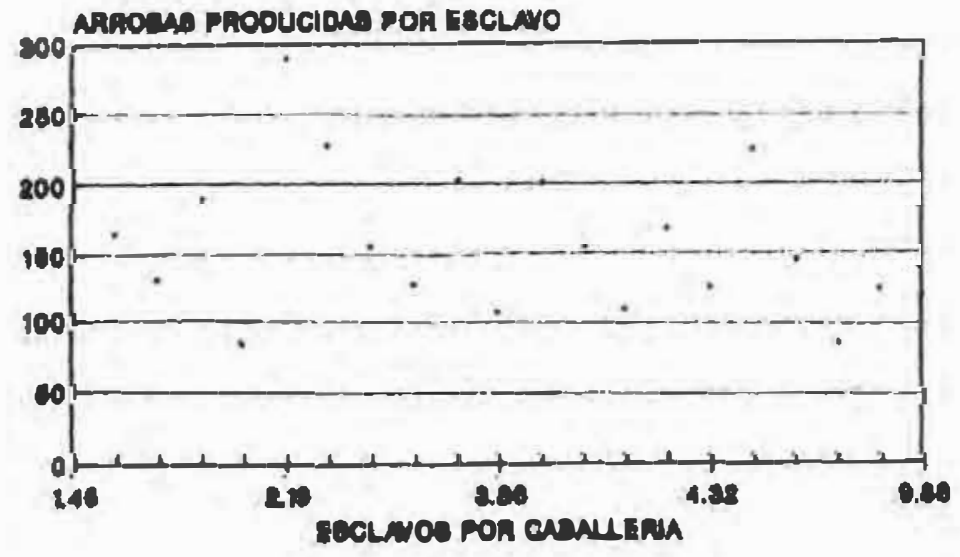

GRÁFICA 6. VALORES PRODUCIDOS POR ESCLAVOS Y ESCLAVOS POR CABALLERIA

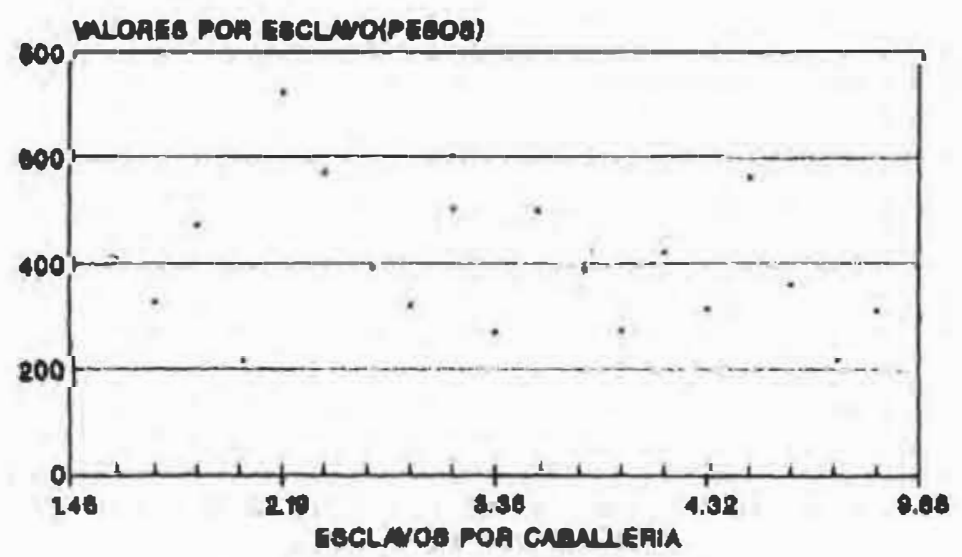


misma realidad bajo el aspecto de los beneficios monetarios conseguidos por esclavo.

Otra cuestión que nos permite hablar de la productividad de los esclavos en los ingenios cubanos es su capacidad de integrarse en todas las labores conducentes a la obtención del azúcar, lo cual hacía que la inversión en esclavos fuese suficiente, sin apenas mayores gastos adicionales en otro personal laboral. Bien es cierto que una serie de operarios libres cooperaban en las tareas agricolas al lado de los negros, pero en oficios sumamente específicos, sobre todo en servicios.

Del total de esclavos que formaban la dotación de los 31 ingenios estudiados, 2.981 aparecen en la documentación con los suficientes datos como para poder ser estudiados. De éstos 2.164 son varones, 803 hembras y de 14 no se cita el sexo.

Su dedicación laboral aparece reflejada del modo siguiente:

\begin{tabular}{lcr}
\hline & Varones & Hembras \\
\hline & 807 & 530 \\
De campo & 788 & 29 \\
Con oficios & 569 & 244 \\
\hline
\end{tabular}

Estas cifras nos permiten observar cómo el número de esclavos con oficios es equiparable al "de campo". Esta proporción, sin embargo, entre las mujeres no se cumple. De la misma manera los datos expuestos vienen a corroborar lo expuesto anteriormente en cuanto a la capacidad de los negros para asumir la mayor parte de las tareas del ingenio y eliminan esa visión del esclavo solamente entregado a tareas "de machete".

A continuación hemos elaborado un Cuadro, donde aparecen, por sexos, el número de esclavos que ejercían los distintos oficios en el ingenio, así como su edad y precio medio según el trabajo ejecutado. 
CUADRO 1. LOS OFICIOS DE LOS ESCLAVOS EN LOS INGENIOS CUBANOS: NUMERO, EDAD Y SUS PRECIOS

\begin{tabular}{|c|c|c|c|c|c|c|}
\hline \multirow[b]{2}{*}{ Oficio } & \multicolumn{3}{|c|}{ Varones } & \multicolumn{3}{|c|}{ Hembras } \\
\hline & № & Edad M. & $\begin{array}{c}\text { Valor M } \\
\text { (Pesos) }\end{array}$ & $\mathbf{N}^{2}$ & Edad M. & $\begin{array}{l}\text { Valor M. } \\
\text { (Pesos) }\end{array}$ \\
\hline De campo & 807 & 26 & 453 & 530 & 27 & 432 \\
\hline Pailero & 141 & 38 & 537 & & & \\
\hline Carretero & 108 & 28 & 531 & 4 & 21 & 438 \\
\hline Tachero & 90 & 36 & 499 & & & \\
\hline Boyero & 77 & 26 & 473 & & & \\
\hline Contramayoral & 36 & 36 & 622 & 1 & 30 & 500 \\
\hline Estanciero & 35 & 48 & 289 & & & \\
\hline Hachero & 33 & 31 & 518 & & & \\
\hline Tejero & 33 & 33 & 568 & & & \\
\hline Carpintero & 32 & 35 & 600 & & & \\
\hline Purgador & 26 & 43 & 392 & & & \\
\hline Aserrador & 23 & 34 & 610 & & & \\
\hline Arriero & 20 & 29 & 540 & & & \\
\hline Alambiquero & & 16 & & 34 & & 534 \\
\hline Cocinero & 16 & 33 & 472 & 4 & 25 & 450 \\
\hline Calderero & 14 & 39 & 589 & & & \\
\hline Albañil & 6 & 36 & 578 & & & \\
\hline Maestro axúcar & 6 & 38 & 592 & & & \\
\hline Enfermera & & & & 7 & 37 & 407 \\
\hline
\end{tabular}

Así pues puede verse cómo las labores del esclavo en el ingenio, alcanzaban prácticamente todas las actividades que se realizaban en el proceso azucarero, lo cual corrobora todo lo expuesto respecto a la capacidad productiva del esclavo en el ingenio. Desde cortadores en el campo, hasta los destinados al manejo de pailas y tachos y a la difícil y delicada tarea de la purga, pasando por los técnicos principales para el proceso de elaboración del fruto como eran los maestros de azúcar. De la misma manera el cuidado de los animales y el manejo de los carros estaban en manos de esclavos, así como otra serie de empleos necesarios para el sostenimiento del ingenio como albañiles o simplemente cocineros. También existian negros carpinte- 


\section{GRÁFICA 7. EDADES MEDIAS POR OFICIOS ENTRE LOS ESCLAVOS VARONES}

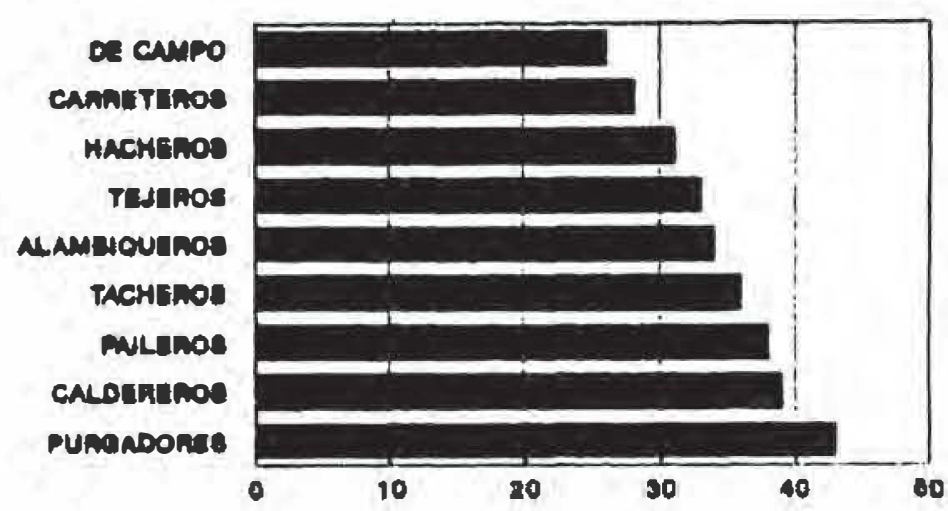

GRAFICA 8. EVOLUCION EDADES MEDIAS DE LOS ESCLAVOS POR TIPOLOGIA LABORAL

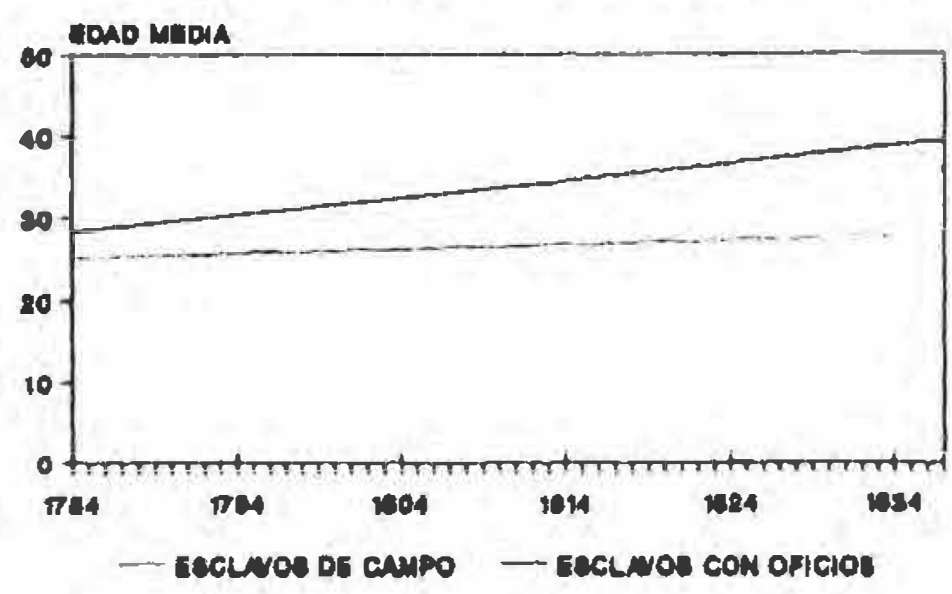

GRÁFICA 9. PRECIOS MEDIOS POR OFICIOS ENTRE LOS ESCLAVOS VARONES (EN PESOS)

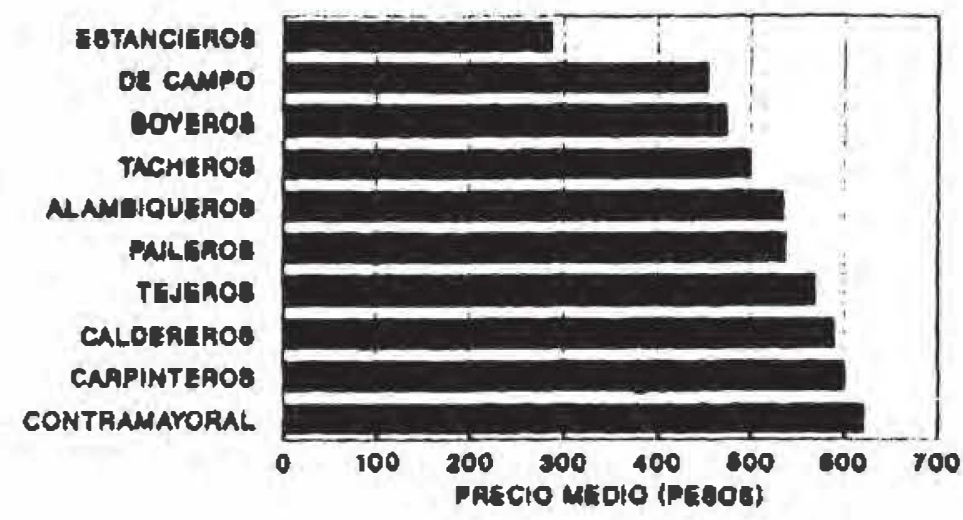

R. I., 1991, n 193 
ros o aserradores para preparar los envases de las cajas que contendrían el dulce.

Naturalmente, los oficios más duros y que requerían poco aprendizaje estaban en manos de los más jóvenes, como indica la Gráfica 7 mientras los más especializados, por la misma razón, eran desarrollados por esclavos de más edad. Esto también nos lleva a decir que el aprendizaje de una determinada tarea, obviamente se realizaba dentro del propio ingenio y que habria un paso gradual de una tarea a otra, entre los esclavos, en función de su incorporación al predio. Esta distribución laboral por edades, enunciada de modo global, si se analiza a lo largo del periodo en todos los ingenios estudiados, como indica la Gráfica 8 , nos aporta los mismos resultados. Unicamente podríamos decir que las edades entre los esclavos sin oficio determinado, mantienen una tendencia constante, mientras las de los especialistas contemplan una subida, hecho que nos corrobora el que cada vez se busque más para tareas específicas a hombres conocedores de ellas y el que conforme avanza el tiempo los ingenios procuren conseguir una mano de obra especializada más experimentada, con el fin de obtener un mejor resultado final en el proceso de elaboración azucarero.

En el mismo orden de cosas, el Cuadro expuesto nos muestra cómo los esclavos más calificados se cotizaban a un precio mayor que los entregados a tareas más elementales. En ese aspecto, la Gráfica 9 nos presenta claramente ese fenómeno que, desde luego, hay que poner también en relación con la edad. Es decir, un esclavo "de campo" alcanzaba mayor precio cuanto más joven fuese, mientras en el que tenía un oficio cualificado contaba más su experiencia. De ese modo se entiende la Gráfica 10 donde se observa que entre los esclavos "de campo" el valor medio es más alto en las edades más vigorosas, mientras en las más adultas decrece. Al contrario que los negros con labores especializadas donde, aparte que por supuesto los más cotizados eran los que unían juventud y especialidad, la veteranía se primaba económicamente mucho más. En definitiva, se pagaba mejor al esclavo en tanto fuese su capacidad productiva por tarea a realizar.

El examen de esta cuestión, entre 1784 y 1837, nos lleva a la misma conclusión. La Gráfica 11 explica cómo a lo largo de todo el periodo estudiado, los esclavos con oficio más especializado se cotizan a mayor precio que el resto de la dotación y cómo la tendencia es que el valor de aquellos suba, mientras el de éstos 
GRÁFICA 10. RELACION DE PRECIOS MEDIOS POR EDAD DE LOS ESCLAVOS SEGUN TIPOLOGIA LABBORAL.

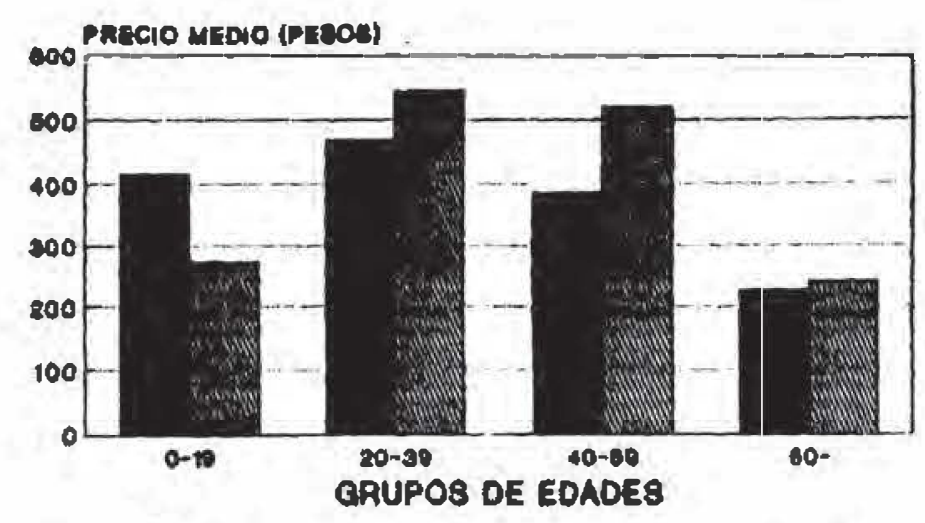

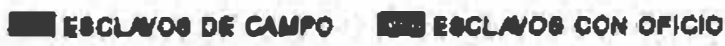

GRÁFICA 11. EVOLUCION PRECIOS MEDIOS DE LOS ESCLAAVOS POR TIPOLOGIA LAEIORAL

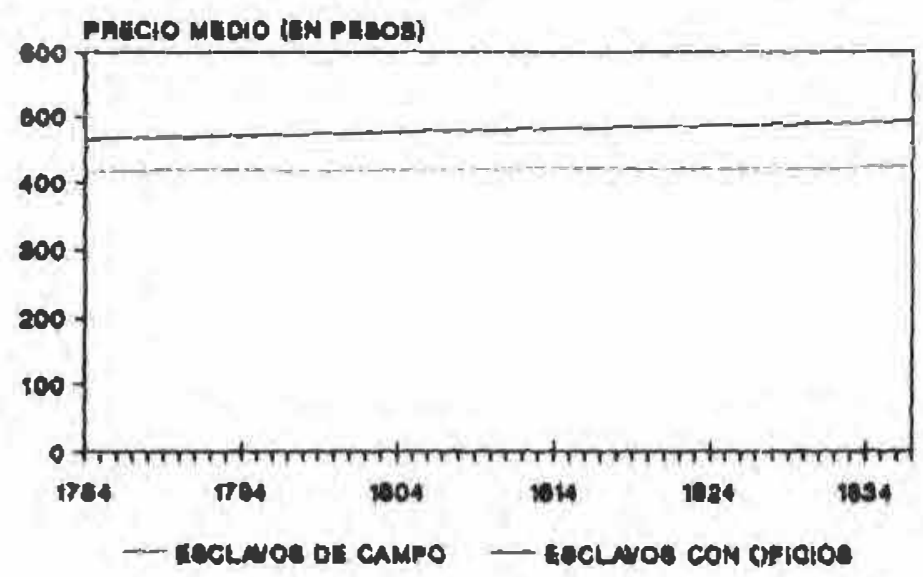

GRAFICA 12. INVERSION EN ESCLAVOS Y PRODUCCION

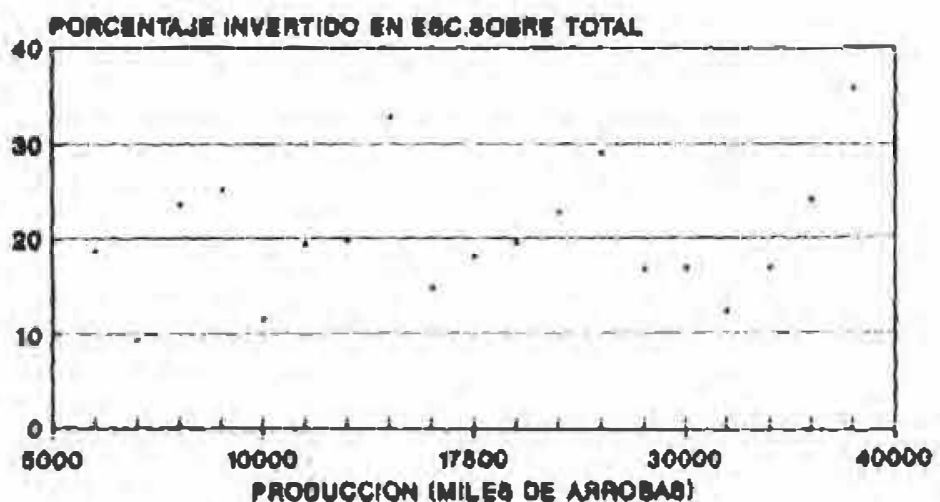

R. I., $1991, \mathrm{n}^{2} 193$ 
se mantenga, hecho esto explicable por las razones que comentamos anteriormente refiriéndonos a la edad.

\section{LA RENTABILIDAD DEL. TRABAJO ESCLAVO}

En esta ocasión, la documentación utilizada no proporciona los datos necesarios para establecer un modelo que nos lleva a conclusiones contables sobre la rentabilidad del esclavo, a través de la diferencia costes/beneficios. En anteriores estudios tuvimos posibilidad de hacerlo y demostrar no sólo esa rentabilidad productiva y financiera sino también el alto interés que proporcionaba la inversión en esclavos (4).

Sin embargo, en este trabajo, queremos volver sobre el punto de la rentabilidad de la labor del esclavo para demostrar ésta a través de dos parámetros. En primer lugar sobre cómo la productividad del negro era lo suficientemente alta como para amortizar su valor en el mercado, sin adición de costos de mantenimiento ni laborales, en un corto espacio de tiempo. En segundo sobre cómo la composición demográfica de la dotación de los ingenios, presenta una serie de caracteres que hacen en sumo grado rentable su capacidad productora.

La inversión hecha en los esclavos del ingenio, constituia una faceta muy importante (Apéndice 3), mucho más si tenemos en cuenta que no era duradera, como es el caso de las tierras y los edificios del ingenio, sino que, aproximadamente cada diez años, vida útil de los esclavos por estos años (5), había que volver a renovar. Con la documentación disponible, podemos afirmar que el contingente esclavo, ya hemos comentado que la media de dotación por todos los ingenios estudiados entre las fechas estudiadas era de 127, tenía un valor medio de alrededor del 20 por ciento del capital total invertido, cifra que parece ser la usual en

(4) Pablo Tornero: "Producción y Costes de los Ingenios de Cuba", Arbor, Madrid, 1991.

(5) Moreno Fraginals [1] y La Historia como arma Barcelona, 1983. Asimismo M. Moreno Fraginals, H. S. Klein y S. Engerman: "Nivel y estructura del precio de los esclavos de las plantaciones de Cuba a mediados del siglo XIX", Revista de Historia Económica, ano 1, n⿳ 1983. Mercedes Garcia Rodriguez: "Ingenios habaneros del siglo XVIII". En Arbor, Madrid, 1991. 
los ingenios de Cuba desde el siglo XVII al XIX (6). Este percentaje unido al que importaba el colocado en tierras, cuya media estaba sobre el 35 por ciento del valor total del ingenio, significaba más de la mitad del capital total del ingenio, como media. El resto estaría representado por maquinaria, edificios y animales. En este orden hay que admitir que sin llegar a definir el ingenio como una industria, sí tiene mucho de modelo industrial, en tanto se concentraban los trabajadores en el propio ingenio, ya que la producción hacia conveniente tener emplazadas en el mismo edificio cierto número de útiles de distinto tipo, de forma que el azúcar en curse de fabricación, pudiese pasar por todos los procesos conducentes a su acabado final. No se olvide que en Cuba el proceso de refino se realizaba en la misma isla, al contrario que en las plantaciones británicas, lo cual especificaba más la producción de azúcar, como un bien industrial. En este sentido, también debemos insistir sobre la adecuación de la inversión en esclavos a la realizada en tierras. Para conseguir unos beneficios por esclavo adecuados a la capitalización en ellos mantenida, era condición no sólo hacer un desembolse importante en la dotación de negros, sino que esta fuese en equilibrio con el resto del montante invertido. Así la Gráfica 12 permite observar cómo no necesariamente el colocar una proporción importante del capital en el ingenio, sobre el factor esclavos, incide en una mayor producción y por tanto en mayores beneficios.

\section{Valores y beneficios de producción y costo de los esclavos}

Ahora queremos referirnos a la capacidad que tenía el hacendado de recuperar el valor, sin costos adicionales, de cada esclavo. Para ello hemos elaborado el Apéndice 4. En él, hemos hallado el precio medio del siervo, resultante de la operación de dividir el valor total de los esclavos de cada ingenio estudiado, y que proporciona cifras de preducción, por el número de negrosi que componian su dotación, o sea, P.M. = V.E./N.E. También hemos hallado el valor de la producción por esclavo, es decir la división

(6) J. Ibarra: "Crisis de la esclavitud patriarcal cubana". Anuario de Estudios Americanos. Vol. XLIII. Sevilla, 1986. En la misma publicación y fecha, Pablo TORNERo "Ingenios, Plantación y Esclavitud". Alejandro Fuente Garcia: "Los ingenios de azúcar en La Habana del siglo XVII (1640-1700). Estructura y mane de ubra". Revista de Historia Económica Año IX, n 1, 1991. Fe IGlesias: "Estructura agraria de La Habana, 1700-1775". Arbor, Madrid, 1991. 
del valor monetario de la cosecha de cada ingenio (a este efecto hemos colocado un precio medio de 2,5 pesos la arroba de azúcar) por la dotación de negros de ese ingenio, o V.P.E. $=$ V.PR/N.E. Y por fin la diferencia entre el precio medio del esclavo y lo producido por él anualmente. Con estos datos, estamos en condiciones de decir que la riqueza generada anualmente por cada esclavo, permitía la recuperación de la inversión en él efectuada, sin los costos adicionales que todo esclavo conllevaba en alimentación, vestido y cuido, en un corto espacio de tiempo, e incluso había ingenios, en los cuales el valor producido por cada esclavo, superaba su propio precio.

Estas mismas fórmulas podemos aplicarlas, globalmente en todos los ingenios, utilizando cantidades promedio. La media de producción entre los predios analizados, dan una cantidad de 20.309 arrobas de azúcar, que multiplicadas por 2,5 pesos, ofrecen unos beneficios anuales por ingenio, sólo en azúcar, de 50.772 pesos.

Si tenemos en cuenta que el valor medio de la dotación de esclavo por finca sumaba 57.373 pesos, resulta que sólo la cosecha azucarera de un año, representaba el 88,49 por ciento del total invertido en negros, insistimos sin los costos anuales generados por éstos. Es más al dividir la cantidad promedio que proporciona el predio por el número medio de esclavos que contienen las fincas que proporcionan datos de producción, en esta ocasión 142, obtenemos que cada esclavo es capaz de rendir una cantidad de 357,55 pesos. Esta cantidad dividida por 404 pesos, precio medio por esclavo, en los predios ahora estudidos, permite decir que prácticamente bastaba una cosecha del ingenio para reponer el capital invertido en la compra de un esclavo. En definitiva y en este aspecto, la rentabilidad financiera del trabajo esclavo estaba perfectamente definida.

\section{Composición demográfica de la población esclava}

Otro aspecto que nos señala la rentabilidad del trabajo esclavo, es su composición demográfica. La primera referencia a tener en cuenta es la división por sexos entre los esclavos, que se presenta muy desigual en función, naturalmente, de que el tipo de trabajo exigía una fuerza física propia de los varones. Como ya enunciamos anteriormente del total de los negros que componían las dotaciones de los ingenios, tenemos datos suficientes para recomponer la actividad de 2.981. Pero en este caso aparecen con 
datos demográficos un total de 2.967. Estos se dividian en 2.164 varones, el 72,59\%, y 803 hembras, el 27,41\%. Esta diferencia tan profunda -que, insistimos, tiene su razón de ser en la productividad - tuvo unas consecuencias sociales y económicas, aparte de demográficas, de trascendencia indiscutible en la esclavitud cubana. No es el momento de referirnos en esta ocasión a esta cuestión, sino señalar solamente que los varones serán mucho más demandados en función de su mayor capacidad productiva. Por eso mismo abundaban más en las dotaciones y, también, por ello el valor medio de esclavos varones era de 429 pesos, mientras el de las hembras bajaba a 362.

De la misma manera, la composición por edad de los esclavos en los ingenios nos lleva a las mismas conclusiones, en cuanto a la productividad de éstos.

Los 2.110 negros varones y 796 hembras de los que tenemos su edad se dividen por grandes grupos del modo siguiente:

\begin{tabular}{lrrrr}
\hline & Varones & \multicolumn{1}{c}{$\%$} & Hembras & $\%$ \\
\hline Hasta 15 años & 166 & 7,86 & 177 & 22,23 \\
De 15 a 59 & 1.827 & 86,60 & 594 & 74,63 \\
Más de 60 & 117 & 5,54 & 25 & 3,14 \\
\hline
\end{tabular}

Queda efectivamente demostrado cómo los mayores porcentajes de esclavos se encuentran en las edades más productivas, considerándose así prácticamente toda la población como activa, y haciendo además que la dependencia demográfica de niños y ancianos sea mínima con respecto a la población de $15-59$ años, es decir al grupo más productivo laboralmente y que, por tanto, los costos de mantenimiento de la población inactiva o menos productiva sean casi inexistentes.

Un examen más pormenorizado, nos lleva a las mismas conclusiones y nos hace ver cómo las edades más productivas, 20-40 años, son las que acaparan el mayor número de esclaves tanto en el caso de los varones como de las hembras, como expresa la Gráfica 13. Naturalmente esto incide de modo acusado en la rentabilidad del esclavo ya que el rendimiento laboral de un negro joven es máximo y su mantenimiento igual del que tuviese más edad. De ahí que, aủn teniendo en cuenta lo matizado en la Gráfica 10, lo que prime en el valor del esclavo sea su edad a la 
hora de valorarse financieramente como demuestra la Gráfica 14. Sin embargo estas condiciones demográficas implican una acusada baja en la tasa de natalidad y al mismo tiempo una elevada tasa de mortandad, lo cual en suma significa, por un lado la incapacidad de reproducción biológica de las dotaciones en la propia isla y por otro, las condiciones de vida tan duras a las que eran sometidos los negros, cuya esperanza de vida a la hora de entrar a trabajar en los ingenios estaba limitada sólo a unos pocos años. Las dos consecuencias demográficas expuestas implicaban en última instancia la absoluta necesidad de reponer constantemente esas dotaciones por medio de importaciones de Africa. Baste para explicar esto que sobre un horizonte de 2.000 esclavos que ofrecen su origen racial, sólo 307 aparecen como

GRAFICA 13. NUMERO DE ESCLAVOS POR EDADES EN LOS INGENIOS

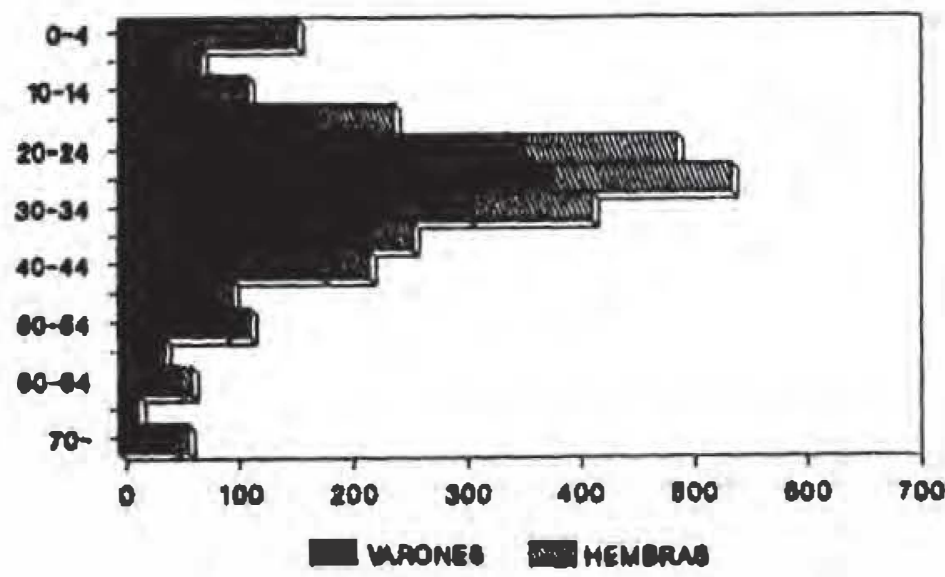

GRAFICA 14. PRECIOS MEDIOS DE ESCLAVOS POR EDADES EN LOS INGENIOS

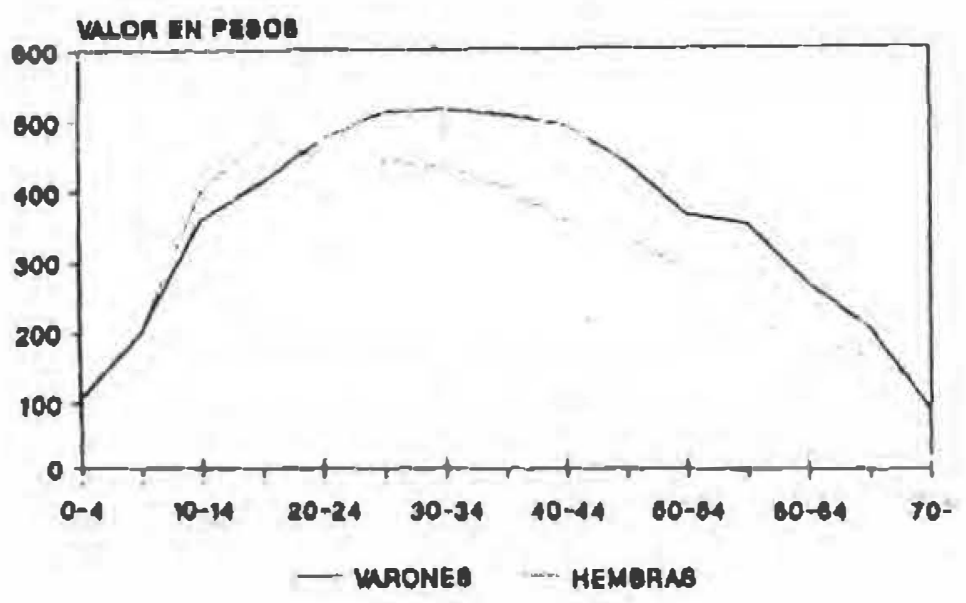

R. 1., 1991, n० 193 
criollos, es decir el 15,35 por ciento. El resto son originarios del continente africano. Sin embargo todo esto se obviaba por parte de los propietarios de fincas azucareras con tal de conseguir una mayor productividad y rentabilidad de sus esclavos. Todo lo expuesto nos permite decir que el trabajo esclavo, en estas fechas (1784-1837) constituía la base de la plantación cubana por su capacidad de producción y su rentabilidad. Por ello mismo se hacía absolutamente necesario para seguir manteniendo el sistema de producción azucarera vigente en la isla y por eso también toda la política de la época estuvo mediatizada por el acontecer esclavista (7).

Desde luego que esto conllevó un cost social, económico, cultural y político de tal trascendencia que determinó la historia de Cuba durante estos años e hipotecó su futuro como nación.

(7) M. Moreno fraginals [1]. En este mismo aspecto, R. Cepero Bonilla: Azúcar y abolición. La Habana, 1948 y F. KNIGHT: Slave society in Cuba during the nineteenth century. Madison, 1979; Pablo TORNERO: "La reacción del poder" cubano ante el fenómeno liberal en España y América". Jahrbuch für Geschichte Lateinmerikas. Hamburgo, $n^{\circ}$ 26. 1989. Ma" del C. BARCiA: Burguesia esclavista y abolición. La Habana, 1987. Asimismo los Estudios sobre la abolición de la esclavilud, Anexo de Revista de Indias, $n^{\otimes} 2$. Madrid, 1985, courdinado por Francisco DE Sol.ano, que reune, entre otros, trabajus de José U. Martinez CaRRERAS ("España y la abolición de la esclavitud durante el siglo XIX") y de Cuncepción NAvarRo Azcue ("La esclavitud de Cuba antes y después de las leyes abolicionistas"). 
APENDICE I

NEGROS ESCLAVOS (NUMERO Y VALOR) EN LOS INGENIOS CUBANOS (EXTENSION, VALOR DE LAS TIERRAS Y PRODUCCION DE AZUCAR). 18841837

\begin{tabular}{|c|c|c|c|c|c|c|c|}
\hline Fecha & Nombre Ingenio & $\begin{array}{l}\text { Extensión } \\
\text { Caballetios }\end{array}$ & $\begin{array}{l}\text { Protumain Azu- } \\
\text { car (Arrobas) }\end{array}$ & $\begin{array}{l}\text { Valor Tierros } \\
\text { (Pesos) }\end{array}$ & $\begin{array}{l}\text { Vabr exclentas } \\
\text { (Pesas) }\end{array}$ & $\begin{array}{c}\text { Valor toial } \\
\text { Ingenio (Resos) }\end{array}$ & $\begin{array}{l}\text { Nimero } \\
\text { esclavor }\end{array}$ \\
\hline 1814 & San Ignacio de Río Blanco & 50.00 & 32000 & 105000 & 54140 & 439182 & 140 \\
\hline 1814 & San Francisco & 50.00 & 18000 & 115000 & - & 332579 & 95 \\
\hline 1799 & Jesús Nazareno & 30.00 & 5000 & 30000 & 20610 & 150000 & 58 \\
\hline 1799 & San Ignacio & 52.00 & 7500 & 36800 & 23420 & 250000 & 76 \\
\hline 1806 & $\begin{array}{l}\text { Nuestra Señora del Rosario } \\
\text { (Pan Seco) }\end{array}$ & 40.00 & 10000 & 60000 & 32550 & 280000 & 76 \\
\hline 1784 & San Luis Gonzaga & 64.00 & 17500 & 66400 & 42120 & 232412 & 106 \\
\hline 1784 & San Joaquin & 45.00 & - & 53400 & 11895 & 105597 & 32 \\
\hline 1803 & San Francisco (Arroyo Naranjo) & 19.00 & 8000 & 51800 & 40400 & 170886 & 73 \\
\hline 1804 & Purísima Concepción & 57.00 & - & 114000 & 29680 & 226040 & 52 \\
\hline 1811 & San Telmo & 32.00 & - & 70830 & 35890 & 186522 & 136 \\
\hline 1811 & San Nicolás & 40.00 & 18246 & 88000 & 39730 & 242586 & 117 \\
\hline 1820 & Nuestra Señora de la Asunción & 34,00 & 15000 & 51750 & 87358 & 267589 & 184 \\
\hline 1820 & San Francisco de Asís & 22.00 & 8000 & 44000 & 33585 & 133314 & 74 \\
\hline 1823 & San Gabriel (Corredera) & 17.00 & 20000 & 30600 & 74230 & 326736 & 168 \\
\hline
\end{tabular}


APÉNDICE I

(continuación)

\begin{tabular}{|c|c|c|c|c|c|c|c|}
\hline Fecha & Nombre Ingenio & $\begin{array}{l}\text { Extensión } \\
\text { Coballerias }\end{array}$ & $\begin{array}{l}\text { Producción Azú- } \\
\text { car (Arrobas) }\end{array}$ & $\begin{array}{l}\text { Valor Tierres } \\
\text { (Pesas) }\end{array}$ & $\begin{array}{l}\text { Valor exclovas } \\
\text { (Pesos) }\end{array}$ & $\begin{array}{c}\text { Valor lotal } \\
\text { Ingenio (Pesas) }\end{array}$ & $\begin{array}{l}\text { Nimero } \\
\text { esclavos }\end{array}$ \\
\hline 1834 & Canas & 44.00 & 30000 & 46125 & 58740 & 352828 & 178 \\
\hline 1834 & San Sebastián & 26.00 & 16548 & 55200 & 23300 & 159022 & 57 \\
\hline 1833 & Jesús María & 52.00 & 30000 & 136750 & 67870 & 404926 & 195 \\
\hline 1836 & San Gabriel & 0.00 & - & - & 81045 & 307004 & 140 \\
\hline 1797 & Nuestra Sra La Concepción & 20.00 & 6000 & 28000 & 19220 & 103145 & 45 \\
\hline 1809 & Nuestra. Sra de Balbanera & 47.00 & 35000 & 116250 & 106200 & 439491 & 242 \\
\hline 1812 & San Diego (Surinam) & 23.00 & - & 50600 & 20695 & 193740 & 54 \\
\hline 1791 & San Francisco de Guatao & 22.00 & 12000 & 39600 & 28800 & 148907 & 95 \\
\hline 1795 & Santísima Trinidad & 34.00 & - & 50627 & 40375 & 142151 & 108 \\
\hline 1791 & Santisima Trinidad de Mariel & 36.00 & 15000 & 57000 & 35100 & 178042 & 117 \\
\hline 1801 & Santa Rosalía & 90.00 & - & 99000 & 25650 & 191352 & 54 \\
\hline 1837 & San Cayetano & 50.00 & 34000 & 95000 & 64759 & 385713 & 168 \\
\hline 1801 & San Felipe & 18.00 & 18000 & 15000 & 37350 & 191532 & 80 \\
\hline 1823 & San Ignacio & 58.00 & 40000 & 99313 & 147950 & 413300 & 321 \\
\hline 1823 & Santa Teresa & 40.00 & 28000 & 60000 & 59850 & 206386 & 139 \\
\hline 1803 & La Providencia & 57.00 & - & 131100 & 75050 & 443197 & 148 \\
\hline 1821 & $\begin{array}{l}\text { San Cristóbal Baracoa-S. Juan } \\
\text { Nepomuceno }\end{array}$ & 0.00 & 40000 & 871250 & 164925 & 1440472 & 404 \\
\hline
\end{tabular}

Fuente: Archivo Nacional de Cuba, Sección Protocolos Notariales: 
APÉNDICE II

\begin{tabular}{|c|c|c|c|c|c|}
\hline Nombre & Fecha & Eutension por Caball & $\begin{array}{l}\text { Extensión en } \\
\text { Coballs. }\end{array}$ & $\begin{array}{l}\text { Producción por escl } \\
\text { (arrobes) }\end{array}$ & $\begin{array}{l}\text { Praducción ingenio } \\
\text { (arrobes) }\end{array}$ \\
\hline San Luis Gonzaga & 1784 & 1.66 & 64.00 & 165.09 & 17500 \\
\hline Santísima Trinidad del Mariel & 1791 & 3.25 & 36.00 & 128.21 & 15000 \\
\hline San Francisco de Guatao & 1791 & 4.32 & 22.00 & 126.32 & 12000 \\
\hline $\begin{array}{l}\text { Nuestra Sra. La Concepción (Cule- } \\
\text { brita) }\end{array}$ & 1797 & 2.25 & 20.00 & 133.33 & 6000 \\
\hline Jesús Nazareno & 1799 & 1.93 & 30.00 & 86.21 & 5000 \\
\hline San Ignacio & 1799 & 1.46 & 52.00 & 98.68 & 7500 \\
\hline San Felipe & 1801 & 4.44 & 18.00 & 225.00 & 18000 \\
\hline San Francisco (Arroyo Naranjo) & 1803 & 3.84 & 19.00 & 109.59 & 8000 \\
\hline $\begin{array}{l}\text { Nuestra Señora del Rosario (Pan } \\
\text { Seco) }\end{array}$ & 1806 & 1.90 & 40.00 & 131.58 & 10000 \\
\hline Nuestra Sra de Balbanera & 1809 & 5.15 & 47.00 & 144.63 & 35000 \\
\hline San Nicolás & 1811 & 2.92 & 40.00 & 155.95 & 18246 \\
\hline San Ignacio de Río Blanco & 1814 & 2.80 & 50.00 & 228.57 & 32000 \\
\hline San Francisco de Asís & 1820 & 3.36 & 22.00 & 108.11 & 8000 \\
\hline Nuestra Señora de la Asunción & 1820 & 5.41 & 34.00 & 86.96 & 16000 \\
\hline $\begin{array}{l}\text { Nepomuceno San Gabriel (Corre- } \\
\text { dera) }\end{array}$ & 1823 & 9.88 & 17.00 & 119.05 & 20000 \\
\hline Santa Teresa & 1823 & 3.48 & 40.00 & 201.44 & 28000 \\
\hline San Ignacio & 1823 & 5.53 & 58.00 & 124.61 & 40000 \\
\hline Jesús Maria & 1833 & 3.75 & 52.00 & 153.85 & 30000 \\
\hline Canas & 1834 & 4.05 & 44.00 & 168.54 & 30000 \\
\hline San Sebastián & 1834 & 2.19 & 26.00 & 290.32 & 16548 \\
\hline San Cayetano & 1837 & 3.36 & 50.00 & 202.38 & 34000 \\
\hline
\end{tabular}

Fuente: Archivo Nacional de Cuba, Sección Protocolos Notariales. 
APÉNDICE III

PORCENTAJE DEL VALOR DE LOS ESCLAVOS EN EL. CAPITAL TOTAL INVERTIDO EN EL INGENIO

\begin{tabular}{|c|c|c|c|c|c|}
\hline Nombre & Feche & $\begin{array}{l}\text { Neineto de } \\
\text { eschnos }\end{array}$ & $\begin{array}{l}\text { Valor de las esclonsas } \\
\text { (en Pesas) }\end{array}$ & $\begin{array}{l}\text { o respacto } \\
\text { al toul }\end{array}$ & $\begin{array}{l}\text { Valor total del } \\
\text { ingenio (en Pesas) }\end{array}$ \\
\hline San Luis Gonzaga & 1784 & 106 & 42120 & 18.12 & 232412 \\
\hline Santisima Trinidad del Mariel & 1791 & 117 & 35100 & 19.71 & 178042 \\
\hline San Francisco de Guatao & 1791 & 95 & 28800 & 19.34 & 148907 \\
\hline $\begin{array}{l}\text { Nuestra Sra. La Concepción (Cule- } \\
\text { brita) }\end{array}$ & 1797 & 45 & 19220 & 18.63 & 103145 \\
\hline Jesús Nazareno & 1799 & 58 & 20610 & 13.74 & 150000 \\
\hline San Ignacio & 1799 & 76 & 23420 & 9.37 & 250000 \\
\hline San Felipe & 1801 & 80 & 37350 & 19.50 & 191532 \\
\hline San Francisco (Arroyo Naranjo) & 1803 & 73 & 40400 & 23.64 & 170886 \\
\hline $\begin{array}{l}\text { Nuestra Señora del Rosario (Pan } \\
\text { Seco) }\end{array}$ & 1806 & 76 & 32550 & 11.62 & 280000 \\
\hline Nuestra Sra de Balbanera & 1809 & 242 & 106200 & 24.16 & 439491 \\
\hline San Nicolás & 1811 & 117 & 39730 & 16.38 & 242586 \\
\hline San Ignacio de Río Blanco & 1814 & 140 & 54140 & 12.33 & 439182 \\
\hline San Francisco de Asís & 1820 & 74 & 33585 & 25.19 & 133314 \\
\hline Nuestra Señora de la Asunción & 1820 & 184 & 87358 & 32.65 & 267589 \\
\hline $\begin{array}{l}\text { San Cristóbal Baracaa-S. Juan Nepo- } \\
\text { muceno }\end{array}$ & 1821 & 404 & 164925 & 11.45 & 1440472 \\
\hline San Gabriel (Corredera) & 1823 & 168 & 74230 & 22.72 & 326736 \\
\hline Santa Teresa & 1823 & 139 & 59850 & 29.00 & 206386 \\
\hline San Ignacio & 1823 & 321 & 147950 & 35.80 & 413300 \\
\hline Jesús Maria & 1833 & 195 & 67870 & 16.76 & 404926 \\
\hline Canas & 1834 & 178 & 58740 & 16.65 & 352828 \\
\hline San Sebastián & 1834 & 57 & 23300 & 14.65 & 159022 \\
\hline San Cayetano & 1837 & 168 & 64759 & 16.79 & 385713 \\
\hline
\end{tabular}


APENDICE IV

DIFERENCIA ENTRE PRECIO MEDIO DEL ESCLAVO Y VALOR PRODUCIDO (EN PESOS)

\begin{tabular}{|c|c|c|c|c|}
\hline Nombre del Ingenio & Fecha & $\begin{array}{l}\text { Valor madio producido } \\
\text { por esclavo }\end{array}$ & $\begin{array}{c}\text { Valor medio del } \\
\text { esclavo }\end{array}$ & $\begin{array}{l}\text { Diferencia } \\
\text { monetaria }\end{array}$ \\
\hline San Luis Gonzaga & 1784 & 412.74 & 397.36 & 15.38 \\
\hline Santísima Trinidad del Mariel & 1791 & 320.51 & 300.00 & 20.51 \\
\hline San Francisco de Guatao & 1791 & 315.79 & 303.16 & 12.63 \\
\hline Nuestra Sra de la Concepción (Culebrita) & 1797 & 333.33 & 427.11 & -93.78 \\
\hline Jesús Nazareno & 1799 & 215.52 & 355.34 & -139.83 \\
\hline San Ignacio & 1799 & 246.71 & 308.16 & -61.45 \\
\hline San Felipe & 1801 & 562.50 & 466.88 & 95.62 \\
\hline San Francisco (Arroyo Naranjo) & 1803 & 273.97 & 553.42 & -279.45 \\
\hline Nuestra Señora del Rosario (Pan Seco) & 1806 & 328.95 & 428.29 & -9934 \\
\hline Nuestra Señora de Balbanera & 1809 & 361.57 & 438.84 & -7727 \\
\hline San Nicolás & 1811 & 389.87 & 339.57 & 50.30 \\
\hline San Ignacio de Rio Blanco & 1814 & 571.43 & 386.71 & 184.71 \\
\hline San Francisco de Asís & 1820 & 270.27 & 453.85 & -183.58 \\
\hline Nuestra Señora de la Asunción & 1820 & 217.39 & 474.77 & -257.38 \\
\hline San Cristóbal Baracoa-S. Juan Nepomuceno & 1821 & 247.52 & 408.23 & -160.71 \\
\hline San Gabriel (Corredera) & 1823 & 297.62 & 441.85 & -144.23 \\
\hline Santa Teresa & 1823 & 503.60 & 430.58 & 73.02 \\
\hline San Ignacio & 1823 & 311.53 & 460.90 & -149.38 \\
\hline Jesús Maria & 1833 & 384.62 & 348.05 & 36.56 \\
\hline Canas & 1834 & 421.35 & 330.00 & 9135 \\
\hline San Sebastián & 1834 & 725.79 & 408.77 & 317.02 \\
\hline San Cayetano & 1837 & 505.95 & 385.47 & 120.48 \\
\hline
\end{tabular}

Fuente: Archivo Nacional de Cuba. Protocolos Notariales. 